\section{JURNAL EKONOMI EFEKTIF}

ISSN : $2622-8882$, E-ISSN : 2622-9935

Jurnal Ekonomi Efektif, Vol. 3, No. 1, Oktober 2020 @ Prodi Manajemen Fakultas Ekonomi Universitas Pamulang

\title{
PENGARUH KEPEMIMPINAN TERHADAP KINERJA KARYAWAN PADA PT. MEGAPRIMA DI JAKARTA
}

\author{
Dede Andi ${ }^{1 *}$, Hafis Laksmana Nuraldy ${ }^{2}$, Imbron $^{3}$ \\ Universitas Pamulang \\ dosen02463@unpam.ac.id*
}

\begin{abstract}
ABSTRAK
Penelitian ini bertujuan untuk mengetahui pengaruh kepemimpinan terhadap kinerja karyawan pada PT. Megaprima di Jakarta. Metode yang digunakan adalah explanatory research dengan sampel sebanyak 95 responden. Teknik analisis menggunakan analisis statistik dengan pengujian regresi, korelasi, determinasi dan uji hipotesis. Hasil penelitian ini variabel kepemimpinan diperoleh rata-rata skor sebesar 3,41 dengan kriteria baik. Variabel kinerja karyawan diperoleh rata-rata skor sebesar 3,83 dengan kriteria baik. Kepemimpinan berpengaruh signifikan terhadap kinerja karyawan dengan persamaan regresi $\mathrm{Y}=7,678+$ 0,899X, dan nilai korelasi 0,787 atau kuat dengan determinasi 61,9\%. Uji hipotesis diperoleh signifikansi $0,000<0,05$.
\end{abstract}

\section{Kata Kunci: Kepemimpinan, Kinerja Karyawan.}

\begin{abstract}
This study aims to determine the effect of leadership on employee performance at PT. Megaprima in Jakarta. The method used is explanatory research with a sample of 95 respondents. The analysis technique uses statistical analysis with regression testing, correlation, determination and hypothesis testing. The results of this study, the leadership variable obtained an average score of 3.41 with good criteria. Employee performance variables obtained an average score of 3.83 with good criteria. Leadership has a significant effect on employee performance with the regression equation $Y=7.678+0.899 X$, and a correlation value of 0.787 or strong with a determination of $61.9 \%$. Hypothesis testing obtained a significance of $0.000<0.05$.
\end{abstract}

Keywords: Leadership, Employee Performance. 


\section{PENDAHULUAN}

\section{A. Latar Belakang Masalah}

Manajemen adalah ilmu seni mengatur proses pemanfaatan sumber daya manusia dan sumber daya lainnya secara efektif dan efesien untuk mencapai suatu tujuan tertentu. Melihat perubahan lingkungan organisasi yang semakin kompleks dan kompetitif, masyarakat perusahaan untuk bersikap lebih responsif agar tetap bertahan. Setiap organisasi dituntut untuk siap menghadapi perkembangan teknologi, kebutuhan konsumen, dan persaingan yang ketat dengan perusahaan lain. Perusahaan yang ingin tetap bertahan harus menghadapi perubahan tersebut dengan strategi masing-masing, salah satu strategi tersebut adalah dengan meningkatkan kinerja karyawannya. Dengan mempertahankan kinerja karyawan tetap tinggi, maka kemungkinan besar perusahaan juga akan mampu bertahan dan berkembang.

Sumber daya manusia (SDM) adalah salah satu faktor yang sangat penting bahkan tidak dapat dilepaskan dari sebuah organisasi, baik institusi maupun perusahaan.SDM juga merupakan kunci yang menentukan perkembangan perusahaan. Pada hakekatnya, SDM berupa manusia yang dipekerjakan di sebuah organisasi sebagai penggerak untuk mencapai tujuan organisasi itu.

Pengertian SDM secara mikro adalah individu yang bekerja dan menjadi anggota suatu perusahaan atau institusi dan biasa disebut sebagai karyawan, buruh, karyawan, pekerja, tenaga kerja dan lain sebagainya. Sedangkang pengertian SDM secara makro adalah penduduk suatu negara yang sudah memasuki usia angkatan kerja, baik yang belum bekerja maupun yang sudah bekerja.

Secara garis besar, pengertian Sumber Daya Manusia adalah individu yang bekerja sebagai penggerak suatu organisasi, baik institusi maupun perusahaan dan berfungsi sebagai aset yang harus dilatih dan dikembangkan kemampuannya.

Marwansyah (2010:3), Sumber Daya Manusia adalah sebagai pendayagunaan sumber daya manusia didalam organisasi, yang dilakukan melalui fungsi- fungsi perencanaan sumber daya manusia, rekrutmen dan seleksi, pengembangan sumber daya manusia, perencanaan dan pengembangan karir, pemberian kompensasi dan kesejahteraan, keselamatan dan kesehatan kerja, dan hubungan industrial.

Kinerja karyawan yang meningkat merupakan salah satu faktor yang m enunjukan efektivitas organisasi dalam mengelola sumberdaya manusianya. Dan merupakan faktor yang penting dalam mendorong produktivitas perusahaan, sehingga kinerja karyawan penting untuk ditingkatkan. Tujuan perusahaan tidak akan tercapai tanpa kinerja yang baik dari karyawannya.

Kemampuan profesional karyawan dapatditingkatkan dengan melakukan pembinaan-pembinaan dan pelajaran dalam tindakan nyata. Upaya peningkatan kemampuan profesional karyawan ini penting dilakukan agar peningkatan kerja dan loyalitas karyawan dapat menjadi kenyataan.

Kepemimpinan menurut Bush (Usman,2011:281) yaitu mempengaruhi tindakan orang lain untuk mencapai tujuan akhir yang diharapkan. Dan menurut Sanusi (Usman, 2011:280) Kepemimpinan yaitu penyatupaduan dari kemampuan, cita-cita, dan semangat kebangsaan dalam mengatur, mengendalikan, dan mengelola rumah keluarga maupun organisasi atau rumah tangga negara. Menurut kunci dalam pencapaian tujuan perusahaan keberhasilan perusahaan dalam mencapai tujuaannya tidak lepas dari kemampuan pemimpinnya dalam mengelola sumberdaya yang dimiliki oleh perusahaan. Sumberdaya tersebut termasuk karyawan yang bekerja di perusahaan. Kepemimpinan dalam perusahaan turut berperan penting dalam meningkatkan kinerja karyawan dan kepemimpinan merupakan salah satu faktor yang mempengaruhi kinerja 
seseorang dalam organisasi. Sutrisno (2009:7) mempunyai definisi sebagai suatu perencanaan, pengorganisasian, pengarahan, dan pengawasan atas pengadaan, pengembangan, kompensasi, pengintegrasian, pemeliharaan, dan pemutusan hubungan kerja dengan maksud untuk mencapai tujuan organisasi perusahaan secara terpadu.

Dalam memimpin sebuah organisasi, seorang pemimpin menggunakan cara-cara atau gaya kepemimpinan.

Ada tiga macam gaya kepemimpinan yaitu gaya kepemimpinan otoriter, demokrasi dan bebas. Gaya kepemimpinan otoriter adalah gaya kepemimpinan yang bersifat otoriter, dimana setiap keputusan berasal dari atasan dan bawahan menjala nkan tugasnya sesuai dengan perintah atasan. Gaya kepemimpinan demokrasi ditandai dengan adanya kerjasama antara atasan dengan bawahan, pengambilan keputusan bersifat kooperatif. Gaya kepemimpinan bebas yaitu kepemimpinan dimana pemimpin memberikan kekuasaan penuh kepada bawahan, pemimpin bersifat pasif.

Wahyudi (2009:120) Kepemimpinan adalah sabagai kemampuan seseorang dalam menggerakkan, mengarahkan sekaligus mempengaruhi pola pikir, cara kerja setiap anggota agar bersikap mandiri dalam bekerja terutama alam pengambilan keputusan untuk kepentingan percepatan pencapaian tujuan yang telah ditetapkan.

Terjadinya permasalahan yang penulis teliti ada beberapa masalahyang pertama terjadinya kurangnya kepemimpinanan dalam bekerja secara efektif, hal tersebut dipengaruhi karena kepemimpinan yang kurang tegas dalam memberi arahan atau tanggung jawab kepada karyawannya, absensi jam keberangkatan dan pulang karyawan yang kurang diwaspadai. Kedua kinerja karyawan yang kurang optimal hal tersebut dipengaruhi kepemimpinan yang kurang memberikan motivasi pada karyawan. Ketiga kurangnya tingkat pengetahuan yang terkait dengan tugas pekerjaan dan akan berpengaruh terhadap kuantitas dan kualitas dari hasil kerja hal tersebut dipengaruhi kurangnya diadakannya pelatihan terhadap karyawan itu sendiri. Keempat kepemimpinan belum mengarahkan motivasi karyawan dipengaruhi adanya karyawan yang kurang optimal dalam bekerja dan hasil yang di berikan kurang efektif untuk perusahaan.

\section{B. Rumusan Masalah}

1. Bagaimana kepemimpinan pada pada PT. Megaprima di Jakarta ?.

2. Bagaimana kinerja karyawan pada PT. Megaprima di Jakarta ?.

3. Adakah pengaruh antara kepemimpinan terhadap kinerja karyawan pada PT. Megaprima di Jakarta?.

\section{Tujuan Penelitian}

1. Untuk mengetahui kondisi kepemimpinan pada PT. Megaprima di Jakarta ?.

2. Untuk mengetahui kondisi kinerja karyawan pada PT. Megaprima di Jakarta ?.

3. Untuk mengetahui pengaruh antara kepemimpinan terhadap kinerja karyawan pada PT. Megaprima di Jakarta?.

\section{METODE PENELITIAN}

\section{Populasi}

Populasi dalam penelitian ini berjumlah 95 responden PT. Megaprima di Jakarta

\section{Sampel}

Teknik pengambilan sampling dalam penelitian ini adalah samplel jenuh, dimana semua anggota populasi dijasikan sebagai sampel. Dengan demikian sampel dalam penelitian ini berjumlah 95 responden. 


\section{Jenis Penelitian}

Jenis penelitian yang dipakai adalah asosiatif, dimana tujuannya adalah untuk mengetahui mencari keterhubungan antara variabel independen terhadap variabel dependennya

\section{Metode Analisis Data}

Dalam menganalisis data digunakan uji validitas, uji reliabilitas, analisis regresi linier sederhana, koefisien korelasi, koefisien determinasi dan uji hipotesis.

\section{HASIL PENELITIAN DAN PEMBAHASAN}

\section{Analisis Deskriptif}

Pada pengujian ini digunakan untuk mengetahui skor minimum dan maksimum skor tertinggi, ratting score dan standar deviasi dari masing-masing variabel. Adapun hasilnya sebagai berikut:

\section{Tabel 1. Hasil Analisis Descriptive Statistics Descriptive Statistics}

\begin{tabular}{|l|r|r|r|r|r} 
& N & Minimum & Maximum & Mean & Std. Deviation \\
\hline Kepemimpinan (X1) & 95 & 28 & 44 & 34.07 & 3.714 \\
\hline Kinerja Karyawan (Y) & 95 & 30 & 49 & 38.29 & 4.240 \\
\hline Valid N (listwise) & 95 & & & &
\end{tabular}

Kepemimpinan diperoleh varians minimum sebesar 28 dan varians maximum 44 dengan ratting score sebesar 3,41 dengan standar deviasi 3,714.

Kinerja karyawan diperoleh varians minimum sebesar 30 dan varians maximum 49 dengan ratting score sebesar 3,83 dengan standar deviasi 4,240.

\section{Analisis Verifikatif.}

Pada analisis ini dimaksudkan untuk mengetahui pengaruh variabel independen terhadap variabel dependen. Adapun hasil pengujian sebagai berikut:

\section{a. Analisis Regresi Linier Sederhana}

Uji regresi ini dimaksudkan untuk mengetahui perubahan variabel dependen jika variabel independen mengalami perubahan. Adapun hasil pengujiannya sebagai berikut:

\begin{tabular}{|c|c|c|c|c|c|}
\hline \multirow[b]{3}{*}{ Model } & \multicolumn{2}{|c|}{ Coefficients $^{a}$} & \multirow[b]{2}{*}{$\begin{array}{l}\text { Standardized } \\
\text { Coefficients }\end{array}$} & \multirow[b]{3}{*}{$t$} & \multirow[b]{3}{*}{ Sig. } \\
\hline & \multicolumn{2}{|c|}{$\begin{array}{l}\text { Unstandardized } \\
\text { Coefficients }\end{array}$} & & & \\
\hline & $\mathrm{B}$ & Std. Error & Beta & & \\
\hline 1 (Constant) & 7.678 & 2.503 & & 3.068 & .003 \\
\hline Kepemimpinan (X) & .899 & .073 & .787 & 12.304 & .000 \\
\hline
\end{tabular}

a. Dependent Variable: Kinerja Karyawan (Y)

Berdasarkan hasil pengujian pada tabel di atas, diperoleh persamaan regresi $\mathrm{Y}$ $=7,678+0,899$ X. Dari persamaan tersebut dijelaskan sebagai berikut:

1) Konstanta sebesar 7,678 diartikan jika kepemimpinan dan motivasi tidak ada, maka telah terdapat nilai kinerja karyawan sebesar 7,678 point.

2) Koefisien regresi kepemimpinan sebesar 0,899 , angka ini positif artinya setiap ada peningkatan kepemimpinan sebesar 0,899 maka kinerja karyawan juga akan mengalami peningkatan sebesar 0,899 point.

\section{b. Analisis Koefisien Korelasi}

Analisis koefisien korelasi dimaksudkan untuk mengetahui tingkt kekuatan hubungan dari variabel independen terhadap variabel dependen baik secara parsial 
maupun simultan. Adapun hasil pengujian sebagai berikut:

Tabel 3. Hasil Pengujian Koefisien Korelasi Kepemimpinan Terhadap Kinerja

\section{Karyawan. \\ Correlations $^{\mathrm{b}}$}

\begin{tabular}{ll|r|r} 
& & $\begin{array}{c}\text { Kepemimpinan } \\
(\mathrm{X} 1)\end{array}$ & $\begin{array}{r}\text { Kinerja Karyawan } \\
(\mathrm{Y})\end{array}$ \\
\hline Kepemimpinan $(\mathrm{X})$ & Pearson Correlation & 1 & $.787^{* *}$ \\
\cline { 2 - 4 } & Sig. (2-tailed) & & .000 \\
\hline Kinerja Karyawan $(\mathrm{Y})$ & Pearson Correlation & $.787^{\star *}$ & 1 \\
\cline { 2 - 4 } & Sig. (2-tailed) & .000 & \\
\hline
\end{tabular}

${ }^{* \star}$. Correlation is significant at the 0.01 level (2-tailed).

b. Listwise $\mathrm{N}=95$

Berdasarkan hasil pengujian diperoleh nilai korelasi sebesar 0,787 artinya kepemimpinan memiliki hubungan yang kuat terhadap kinerja karyawan.

\section{c. Analisis Koefisien Determinasi}

Analisis koefisien determinasi dimaksudkan untuk mengetahui besarnya persentase pengaruh dari variabel independen terhadap variabel dependen. Adapun hasil pengujian sebagai berikut:

Tabel 4. Hasil Pengujian Koefisien Determinasi Kepemimpinan Terhadap

Kinerja Karyawan.

Model Summary

\begin{tabular}{|c|c|c|c|c|}
\hline Model & $\mathrm{R}$ & R Square & $\begin{array}{l}\text { Adjusted R } \\
\text { Square }\end{array}$ & $\begin{array}{l}\text { Std. Error of the } \\
\text { Estimate }\end{array}$ \\
\hline 1 & $.787^{a}$ & .619 & .615 & 2.629 \\
\hline
\end{tabular}

Berdasarkan hasil pengujian diperoleh nilai determinasi sebesar 0,619 artinya kepemimpinan memiliki kontribusi pengaruh sebesar $61,9 \%$ terhadap kinerja karyawan.

\section{d. Uji Hipotesis}

Pengujian hipotesis dengan uji t digunakan untuk mengetahui hipotesis mana yang diterima.

Rumusan hipotesis: Terdapat pengaruh yang signifikan antara kepemimpinan terhadap kinerja karyawan.

Tabel 5. Hasil Uji Hipotesis Kepemimpinan Terhadap Kinerja Karyawan.

\section{Coefficients $^{\mathrm{a}}$}

Unstandardized

Coefficients

Standardized

\begin{tabular}{|c|c|c|c|c|c|}
\hline \multirow[b]{2}{*}{ Model } & \multicolumn{2}{|c|}{ Coefficients } & \multirow{2}{*}{$\begin{array}{l}\text { Coefficients } \\
\text { Beta }\end{array}$} & \multirow[b]{2}{*}{$\mathrm{t}$} & \multirow[b]{2}{*}{ Sig. } \\
\hline & $\mathrm{B}$ & Std. Error & & & \\
\hline $\begin{array}{ll}1 & \text { (Constant) }\end{array}$ & 7.678 & 2.503 & & 3.068 & .003 \\
\hline Kepemimpinan (X) & .899 & .073 & .787 & 12.304 & .000 \\
\hline
\end{tabular}

a. Dependent Variable: Kinerja Karyawan (Y)

Berdasarkan hasil pengujian pada tabel di atas, diperoleh nilai t hitung $>\mathrm{t}$ tabel atau $(12,304>1,986)$, dengan demikian hipotesis yang diajukan bahwa terdapat pengaruh yang signifikan atara kepemimpinan terhadap kinerja karyawan diterima.

\section{PEMBAHASAN HASIL PENELITIAN}

\section{Kondisi Jawaban Responden Variabel Kepemimpinan}

Berdasarkan jawaban responden, variabel kepemimpinan diperoleh ratting score sebesar 3,41 berada di rentang skala 3,40 - 4,19 dengan kriteria baik atau setuju.

\section{Kondisi Jawaban Responden Variabel Kinerja Karyawan}

Berdasarkan jawaban responden, variabel kinerja karyawan diperoleh ratting score 
sebesar 3,83 berada di rentang skala 3,40 - 4,19 dengan kriteria baik atau setuju.

\section{Pengaruh Kepemimpinan Terhadap Kinerja Karyawan}

Kepemimpinan berpengaruh signifikan terhadap kinerja karyawan dengan persamaan regresi $\mathrm{Y}=17,517+0,565 \mathrm{X}$, nilai korelasi sebesar 0,787 atau memiliki hubungan yang kuat dengan kontribusi pengaruh sebesar 61,9\%. Pengujian hipotesis diperoleh nilai t hitung $>\mathrm{t}$ tabel atau $(12,304>1,986)$. Dengan demikian hipotesis yang diajukan bahwa terdapat berpengaruh signifikan antara kepemimpinan terhadap kinerja karyawan diterima.

\section{PENUTUP}

\section{Kesimpulan}

a. Variabel kepemimpinan diperoleh ratting score sebesar 3,41 berada di rentang skala 3,40 - 4,19 dengan kriteria baik atau setuju.

b. Variabel kinerja karyawan diperoleh ratting score sebesar 3,83 berada di rentang skala 3,40 - 4,19 dengan kriteria baik atau setuju.

c. Kepemimpinan berpengaruh signifikan terhadap kinerja karyawan dengan persamaan regresi $\mathrm{Y}=17,517+0,565 \mathrm{X}$, nilai korelasi sebesar 0,787 atau kuat dan kontribusi pengaruh sebesar $61,9 \%$ sedangkan sisanya sebesar $57,9 \%$ dipengaruhi faktor lain. Uji hipotesis diperoleh nilai thitung $>\mathrm{t}$ tabel atau $(12,304>1,986)$.

\section{Saran}

a. Pimpinan hendaknya selalu memberikan bimbingan kepada karyawan menyelesaikan pekerjaan.

b. Perusahaan harus melakukan peltihan dalam meningkatkan kemampuan skill karyawan sehingga mampu menyelesaikan pekerjaan dengan baik.

\section{DAFTAR PUSTAKA}

Abdullah, M (2014) Manajemen dan Evaluasi Kinerja Karyawan, Yogyakarta: Penerbit Aswaja Pressindo.

Dessler, G. (2006.) Manajemen Sumber Daya Manusia (Jilid II). Jakarta: Indeks.

George Terry R \& Rue, Leslie W. Rue (2016) Dasar-Dasar Manajemen, Jakarta Bumi Aksara.

Gerry Dessler (2016) Human Resources Management, Prenticehall, London: International Inc.

Hasibuan, Malayu S.P. (2016). Manajemen Sumber Daya Manusia. Edisi Revisi. Jakarta: PT Bumi Aksara.

Imam Ghozali (2017). “Aplikasi Analisis Multivariate Dengan Program SPSS”. Edisi Kelima. Semarang: Badan Penerbit Undip.

Istijanto (2014) “Riset Sumber Daya Manusia”. Jakarta: PT. Gramedia Pustaka

Jasmani, J., \& Paeno, P. (2019). The Effect of Leadership and Competence on Lecturer Performance and Its Implications on Student Learning Motivation at Pamulang University. International Journal of Advances in Social and Economics, 1(4).

Luthans Fred (2014) Organizational Behavior, Ney York: McGraw-Hill, New York.

Mangkunegara, Prabu Anwar. (2016). Evaluasi Kinerja SDM. Cetakan ke tujuh, PT Refika Aditama: Bandung.

Pranoto, P., Jasmani, J., \& Marayasa, I. N. (2019). Pelatihan Digital Marketing Untuk Peningkatan Perekonomian Anggota Karang Taruna Al Barkah Di Kampung Cicayur-Tangerang. Jurnal Pengabdian Dharma Laksana, 1(2), 250-258.

Prasada, D., Sunarsi, D., \& Teriyan, A. (2020). Pengaruh Etos Kerja Dan Kompensasi 
Terhadap Komitmen Organisasi Pada DHL Logistic Di Jakarta. JENIUS (Jurnal Ilmiah Manajemen Sumber Daya Manusia), 4(1), 51-60.

Robbins, P.S, \& Judge, A.T. (2003). Organizational Behavior. Jakarta: Salemba Empat. Rozi, A., \& Sunarsi, D. (2020). The Influence of Motivation and Work Experience on Employee Performance at PT. Yamaha Saka Motor in South Tangerang. Jurnal Office, 5(2), 65-74.

Sobarna, A., Hambali, S., Sutiswo, S., \& Sunarsi, D. (2020). The influence learning used $\mathrm{ABC}$ run exercise on the sprint capabilities. Jurnal Konseling dan Pendidikan, 8(2), 67-71.

Sugiyono (2017), "Metode Penelitian Administrasi : dilengkapi dengan Metode $R \&$ $D$ ". Bandung: Alfabeta.

Sunarsi, D. (2018). Buku Ajar: Seminar Perencanaan Sumber Daya Manusia. Tangerang Selatan: Asmoro Mediatama

Sunarsi, D. (2018). Pengembangan Sumber Daya Manusia Strategik \& Karakterisrik Sistem Pendukungnya : Sebuah Tinjauan. Jurnal Ilmiah MEA (Manajemen, Ekonomi, \& Akuntansi), 2(3), 178 - 194

Veithzal Rivai (2015) Manajemen Sumber Daya Manusia Untuk Perusahaan, Jakarta: Raja Grafindo Persada.

Wibowo (2015) Manajemen Kinerja, Jakarta: PT. Raja Grafindo Persada

Yuangga, K. D., \& Sunarsi, D. (2018). The Influence of Procrastination and Low Time Management on Student Self Efficacy (at MA Soebono Mantofani). PINISI Discretion Review, 2(1), 85-92. 